\title{
Exceder a Naturaleza pintando. Una lectura de Mirad a quién alabáis, de Lope de Vega
}

\author{
Enrico Di Pastena \\ Università di Pisa \\ enrico.dipastena@unipi.it
}

Recepción: 26/06/2017, Aceptación: 13/07/2017, Publicación: 22/12/2017

\section{Resumen}

El andamiaje argumental de Mirad a quién alabáis, comedia palatina de la madurez de Lope (princeps: 1621), se sustenta en los retratos verbales que diferentes personajes hacen de la extraordinaria hermosura de Juana Esforcia, Duquesa de Milán. La utilización constante a lo largo de la pieza de referencias pictóricas permite ver estos retratos, de remota ascendencia petrarquista, como una manifestación ecfrástica, a la dama retratada como una viva obra de arte y, sobre todo, al dramaturgo como un insuperable "pintor». Así, la capacidad que poseen las descripciones de suscitar pasiones en escena se convierte en última instancia en un testimonio más, si no en un alarde, de la maestría formal de Lope en ańos convulsos para su reinado literario y dramático, al mismo tiempo que una mise en abyme de su arte teatral.

Palabras clave

Lope de Vega; Mirad a quién alabáis; comedia palatina; écfrasis; retrato femenino

\begin{abstract}
Overcoming Nature through Painting: An Interpretation of Mirad a quién alabáis by Lope de Vega

The architecture of Mirad a quién alabáis, a palatine comedy of Lope de Vega's later life (princeps: 1621), rests on the verbal portraits that various characters realize of the extraordinary beauty of Juana Esforcia, Duchess of Milan. The constant use of pictorial references impels to see such portraits, of remote Petrarchan origin, as a manifestation of ekphrasis, the lady portrayed as a vivid work of art and, above all, the playwright as an unsurpassed "painter". Thus, the ability of descriptions to arouse passions on the scene
\end{abstract}


becomes a further testimony, when not a glimpse, of Lope's formal mastery during what were convulsive years for his literary and dramatic realm, as well as a mise en abyme of his theatrical art.

\section{Keywords}

Lope de Vega; Mirad a quién alabáis; palatine play; ekphrasis; femenine portrait

Mirad a quién alabáis se imprimió por primera vez en 1621, en la Parte XVI de comedias de Lope de Vega. El dramaturgo debió de escribirla en los años inmediatamente anteriores, probablemente entre 1619 y $1620 .^{1}$ Es una comedia palatina que se inclina hacia la modalidad seria, por el tono en ciertos momentos ejemplar y por cómo trata el tema de la lealtad al poder real: ${ }^{2}$ la acción plantea el antagonismo entre el rey Alonso de Aragón y un vasallo suyo de rango elevado, el Almirante de Nápoles don César, quien al final logra el premio de su lealtad.

A pesar de ser en todo momento fiel al monarca, el Almirante provoca su resentimiento por haberle alabado de forma encarecida la hermosura y las virtudes de la noble con la que Alonso ha planeado casarse. El asunto que desencadena la intriga se resume, pues, en el título de la obra: hay que ser precavidos con el objeto de los elogios. Por otro lado, desde el primer acto de la pieza se hace evidente que importa, y mucho, también el cómo se articula el encomio y el grado de

1. Véanse los datos razonados sobre la datación y las compañías que tuvieron en su repertorio la obra en la edición de Di Pastena (2017).

2. Cf. Antonucci (2013: 148-149). Sobre esta veta, véase ahora Zugasti (2015), con bibliografía. Y cf. Arata (1989: 49-55), Ojeda Calvo (1996: 97-104), Ferrer Valls (1997), Oleza (1997: 250), Oleza y Antonucci (2013: 700-705), Badía Herrera (2015: 106). 
entusiasmo con el que el elogiador es partícipe de su discurso (en ese sentido, el título bien podría haber sido Mirad cómo o cuánto alabáis). Lope manifiesta que la alabanza se puede malentender ya en la dedicatoria de la obra, dedicatoria que debió de escribirse, según solía pasar, en vista de la impresión de la comedia y por lo tanto después de que esta hubiera dejado de constituir una novedad en las tablas. El autor consagra el texto prologal a la dama portuguesa doña María de Noroña, mujer de Diego Jiménez de Vargas, caballero de la orden de Santiago y a su vez dedicatario, no muy conocido hoy en día, de otra comedia que vio la luz en la Parte XVI: La inocente Laura. Si el paratexto, como era de esperar, está encaminado al elogio de la dama y de su esposo, también cabe destacar que sus reflexiones parecen relacionarse más directamente que en otras ocasiones con la pieza que preceden. En la dedicatoria Lope reconoce cuatro motivaciones principales para la alabanza (lisonja, amor, obligación y miedo) y considera que de muchas maneras puede esta suscitar sospechas; en el interior de la comedia es el Rey quien utiliza algunas de estas distinciones (vv. 505-518). Lo cierto es que también en el «Prólogo dialogístico» que antepone a la Parte XVI y en el que hablan el Teatro y un Forastero se alude, junto con tramoyas y tipos de público, a un Lope que «en sus libros dice bien de otros poetas», cuando "Todos dicen mal de él»: la alabanza, si generosa y sincera, evidentemente asume para el Fénix, que se dispone a abordar los lustros conclusivos de su trayectoria vital y artística deseando una plaza confortable, un valor central, aunque también evoque a su temido contrario, ese vituperio del que el autor se ha sentido injustamente blanco (incluso por mano de "la barbada ignorancia de muchos que visten seda", tal como añade en el mismo prólogo, en probable alusión a una comedia que le había sido silbada), ahora que una nueva generación de dramaturgos apremia. ${ }^{3}$

Mirad a quién alabáis es una obra rica de resonancias pictóricas y vuelve a activar explícitamente el motivo, difundidísimo en el Siglo de Oro, de la correspondencia entre poesía y pintura («ut pictura poesis»), entre poeta y pintor; el dicho descendía de una malinterpretación de Horacio y contaba con el precedente del aforismo de Simónides de Ceos, que hacía de la pintura "una poesía muda" («muta poesis») y de la poesía «una pintura que habla» («pictura loquens»). ${ }_{4}^{4}$ Consideramos que esa relación consabida, e incluso trillada, se convierte, en manos de Lope y en el transcurso de Mirad a quién alabáis, en un implícito instrumento de reivindicación de su propia maestría dramática y poética. Por lo demás,

3. Sobre el prólogo, véanse la ficha correspondiente en Les idées du théâtre, firmada por d'Artois, y ahora Giuliani y d'Artois (2017: 27-28), quienes señalan, además, cómo la crítica a la lisonja asoma en las dedicatorias de varias comedias de la Parte XVI; con ella Lope se afirmaría a sí mismo como autor que no necesita elogios falsos o excesivos y que se impone por la evidencia del valor de su producción.

4. Un panorama, en el clásico estudio de Aurora Egido (1990), al que se pueden añadir Civil (1996), Lleó Cañal (2007), Arredondo Sirodey (2008) y Martín Gayango (2013). Véase también, desde la vertiente de la pintura, Calvo Serraller (1991). 
sabemos que son frecuentes los contactos entre el Fénix y la pintura, y los ecos que esta deja en su corpus, también con finalidades estratégicas y de autopromoción, como metáfora de su literatura. ${ }^{5}$

En Mirad a quién alabáis esas relaciones cristalizan en una auténtica red de ocurrencias léxicas. El personaje que más cumplidamente acerca la poesía y la pintura es el Rey, la figura que teme las causas recónditas y los efectos manifiestos del arrobo descriptivo. En un largo romance Alonso de Aragón desahoga ante Otón su malestar y sospechas (vv. 397-438):

\begin{tabular}{|c|}
\hline $\begin{array}{l}\text { «Ángel, cielo, serafín, } \\
\text { rosas, jazmín, azucenas, } \\
\text { claveles, púrpura, sol, } \\
\text { oro, diamantes y perlas» } \\
\text { era lo menos, Otón. } \\
\text { ¿No has visto la lisonjera } \\
\text { pluma guïada de amor } \\
\text { de un dulcísimo poeta, } \\
\text { que de los cielos más altos } \\
\text { desencaja las estrellas? } \\
\text { Va por rubíes a Ceilán, } \\
\text { por jazmines a Valencia, } \\
\text { por diamantes a la China, } \\
\text { por alabastros a Grecia; } \\
\text { no deja cándido cisne } \\
\text { que no diga que le afrenta } \\
\text { su cuello y que es con sus manos } \\
\text { la nieve, en los Alpes, negra. } \\
\text { ¿No has visto, Otón, un pintor } \\
\text { cómo en la tablilla ordena } \\
\text { el blanco, el azul, el rojo, } \\
\text { la sombra, el nácar que templa, } \\
\text { mezcla el carmín para el labio, } \\
\text { y para las joyas mezcla } \\
\text { el pajizo y genolí, } \\
\text { que de ser oro se precia, } \\
\text { y cómo tiento y pincel } \\
\text { tiene en la mano siniestra } \\
\text { y con la derecha excede } \\
\text { tal vez a naturaleza? }\end{array}$ \\
\hline
\end{tabular}

5. Han sido abordados recientemente por Sánchez Jiménez (2011), donde se encuentran referencias bibliográficas más específicas, a las que es posible añadir Entrambasaguas (1975), Ambrose (2004) y ahora, para la primera época de Lope, Pedraza Jiménez (2012). Antes, véanse Vosters (1990) y Portús Pérez (1992, 1999); recogen lugares lopianos sobre arte pictórico y pintores Camón Aznar (1945: 233-252) y sobre «Pintura y poesía» Pérez y Sánchez Escribano (1961: 137-173). Hay alguna referencia a pintores y al arte correspondiente también en Rennert y Castro (1968: 387-390). 


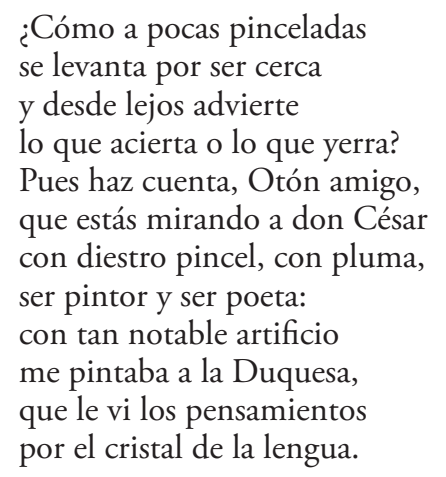

Lo explícito del paralelismo, el desarrollo de la argumentación por parte del personaje, las reacciones emotivas que provoca en él y las repercusiones que tendrá para la intriga, sirvan para justificar la extensión de la cita (y la comodidad del lector valga a motivar la extensión de las que vamos a reproducir más adelante). El Rey no se limitará a apartar de su vista al vasallo presuntamente infiel, sino que resolverá anular la boda que tenía prevista y cuyos fines eran en lo esencial políticos. A los ojos de su señor, César ha actuado como un artista que con pluma y pincel ideales no ha podido evitar que se delatara su (a estas alturas solo presunta) implicación afectiva con el objeto descrito. ${ }^{6}$ Lo irónico de la situación es que la inquebrantable lealtad del Almirante no le ha permitido albergar al inicio pensamientos maliciosos y, en cambio, la anulación del compromiso matrimonial que en el Rey producen las sospechas acabará favoreciendo precisamente la unión entre don César y la Duquesa. Otra y más encubierta alusión antifrástica en el episodio podría detectarse en que la conducta del Monarca es una posible inversión de la de un dechado de magnanimidad, Alejandro Magno, quien según una conocida anécdota renunció a su concubina Campaspe para beneficiar a quien tenía el encargo de pintarla (en este caso materialmente), es decir, Apeles. ${ }^{7}$ En último lugar, el repudio por parte de la figura real también podría interpretarse como una suerte de inversión del amor de lejos o de oídas. Anteriormente, a la afirmación de Roberto por la que "puédese amar sin ver» (v. 37), y aun reconociendo el poder figurativo de la imaginación (calificada de «pintora» en el v. 50), Alonso se ha negado a doblarse a su fuerza y ha declarado

6. Demasiado vaga parece la referencia en los vv. 427-430 como para ver en ella una indirecta alusión a El Greco, tal como en cambio señaló Camón Aznar (1970: II, 1216).

7. La anécdota, muy conocida, se cuenta en Plinio, Naturalis Historia (XXXV, xxxvı, 85-87, 324-325). Que Lope pudo haberla tenido en cuenta lo confirmaría que más adelante en el texto otro personaje, Roberto, la evoque; el Fénix dramatizó el episodio en el primer acto de La grandeza de Alejandro (esp. vv. 587-648), comedia que también se imprimió en la Parte XVI de sus comedias. 
que prefiere objetivos más tangibles. ${ }^{8}$ Con todo, cuando el Rey vea a la Duquesa sin conocer su identidad y solo sospechando su elevada condición social, no podrá sino celebrar los irresistibles encantos de la dama.

La reacción, algo desaforada, que en el Monarca suscita el elogio hecho por su Almirante parece cimentarse en una especie de afrenta de lesa majestad y en unos celos mal entendidos. ${ }^{9}$ Se aprecia quizás cierta «debilidad» o inconsistencia de ese desencadenante de la acción, aunque el mismo criado de don César, Fabio, se dejará escapar más adelante: "parece imposible / alabar y no querer» (vv. 1475-1476). Alonso, que presenta las limitaciones del tipo del rey mozo y galán, se ve arrastrado por sus fantasmas, quizás proyección involuntaria de su propia actitud de seductor empedernido. Se le ve en los primeros compases de la comedia acechar nada menos que a la hermana del Almirante, el hombre al que ha alejado de Nápoles encargándole la misión de traer a la ciudad la futura reina y al que reprochará una conducta despreciable. Una situación inicial, la del cortejo ilícito, que Lope recuperará en El castigo sin venganza, donde el Duque de Ferrara prosigue sus correrías nocturnas a pesar de que sea inminente la llegada de su prometida Casandra, pero con la diferencia de que en la suma tragedia lopiana resuena en escena, en boca de Cintia (vv. 93-128), una condena explícita de la conducta del mandatario, circunstancia que no se da en Mirad a quién alabáis. Dicho sea de paso: si el antagonismo amoroso entre el rey y un vasallo (figura en nuestro caso relevante, al tratarse, como vimos, de un Almirante, y además deudo del monarca, pues es su primo) resulta un rastro persistente de una de las manifestaciones de un motivo, el de los abusos de poder, muy presente en la fase de arranque del subgénero palatino, ${ }^{10}$ cabe observar que la situación recibe ahora un tratamiento suavizado, al privilegiar la intriga, sobre los desmanes del poderoso, las dudas del subalterno ante la disyuntiva entre lealtad y logro de sus intereses amorosos, $\mathrm{y}$ al acabar la comedia de manera feliz.

En el segundo acto de nuestra comedia, Alonso de Aragón vuelve a manifestar su disgusto ante otra descripción que de la Duquesa hace el Almirante. Este la presenta en el campo de batalla en su vertiente de mujer guerrera como una nueva amazona, sigue comparándola con conocidas figuras del pasado como Semíramis y Escipión el Africano ("Cipión» en el texto: v. 1289), añade a sus

8. Véanse los vv. 41-56: «Rey Aunque la imaginación / suele pintar al deseo / lo que no ha visto, y yo creo / que sus efectos lo son, / no tiene fuerza conmigo, / pues nunca la imaginé / ni por fama vista fue / la causa que adoro y sigo. / No pide mi pensamiento / retratos a la pintora / imaginación, ni adora / la ley del merecimiento. / No quiero, formando ideas, / lo no visto por lo visto, / que lo que he visto conquisto / y hoy quiero que tú lo veas».

9. Estos, motor poderoso para la intriga de numerosas comedias del Siglo de Oro, se harán aún más descubiertos en las palabras con que Octavio, v. 1989, califica la decisión de Alonso de encarcelar a César ante el acuerdo, entre la Duquesa y el Almirante, que sigue al falso enfrentamiento en armas entre la de Milán y el adalid; para Celia el «airado» Alfonso (v. 2121) es movido de «envidias» (v. 2123) desencadenadas por la pérdida de la importante mujer y el correspondiente condado.

10. Cf. Badía Herrera (2014: 280 ss.). 
términos de comparación un diamante y culmina el parlamento equiparándola a un ángel, San Miguel. La crítica del Rey no podría ser más tajante, pues considera "desatinos / tantos encarecimientos» (vv. 1300-1301) y «diabólico desatino» (v. 1308) las metáforas usadas por el Almirante; acto seguido, le encarga a don César el mando de las tropas que tendrán que cortarle el paso a la enemiga.

Cuando, como veremos, sea Roberto quien se lance a la descripción encarecida de una peregrina ignorando que bajo su traje esconde su identidad la misma Duquesa, el Rey, sorprendido porque el interlocutor se expone al riesgo de incurrir a su vez en el exceso de elogios —el error ya cometido por el Almirante-, asimila el discurso del otro a la obra del pincel nombrando nada menos que a Zeuxis: «¿y así tu pincel la precia, / que Zeusis no le igualó / cuando a Elena retrató, / de cinco damas de Grecia?» (vv. 2041-2044). Lope se hace eco aquí de una conocida anécdota transmitida por Plinio y retomada por polianteas como la de Pedro Mexía, ${ }^{11}$ y prepara la situación paradójica en la que finalmente será el propio Rey quien cante los elogios de la hermosura de la peregrina (vv. 22902336; volveremos sobre ello), y lo haga, según una clara inversión de papeles, en presencia de don César y antes de descubrir, en la inminencia del desenlace, que se trata de su antigua prometida, que él habrá perdido para siempre.

Finalmente, el mismo Roberto, después de haber rebajado con una captatio su condición («Ni yo puedo ser Apeles [...]», v. 1806), relaciona sus palabras con los trazos del pincel para ensalzar a su señor y celebrar su poder («mi boca hará pinceles / para pintar cada día / tus alabanzas, señor», vv. 1807-1809).

Antes de seguir con nuestras argumentaciones, subrayaremos que, además de aprovechar la conexión entre el binomio pincel-pluma, Lope en la obra parece propenso a potenciar la polisemia de ese segundo vocablo (y tampoco ello es insólito): si en más de una ocasión la pluma es el instrumento del "retratista», en otras ocurrencias corresponde al adorno militar, pues el ejército de Nápoles se presenta «de banderas y plumas coronado» (v. 1520), «arrogancias y plumas presta al viento» (v. 1527), anticipando de esa manera la entrada en escena, al mando de las tropas, de don César, "muy bizarro con plumas y con un bastón" (acotación que sigue al v. 1530). El hecho de que César reúna la capacidad de «escribir» retratos y de combatir (aunque no necesite hacer lo segundo) se manifiesta, pues, a través de la pluma. Esta, sin embargo, también puede valer para significar, en el estandarte de las tropas milanesas, la incapacidad de mantener fe a la palabra dada y referirse por lo tanto al Rey («por mostrar en suma / que hay palabra que pesa como pluma», vv. 1495-1496), como parte de una más elaborada representación gráfica, un emblema, en que caben los platillos de una balanza y las dos manos que ya no están destinadas a unirse en matrimonio. Por

11. Pedro Mexía, Silva de varia lección, lib. II, cap. 17, 642-643. Y antes, Plinio, Naturalis historia, XXXV, XXXvi, 64, p. 309 (referencia a las cinco doncellas de Agrigento) y 66 (alusión a una estatua de Elena conservada en Roma). 
su parte, el Rey aludirá con la pluma a la vívida imagen de un cometa («en la imitación / de pluma resplandeciente», vv. 2163-2164). No falta una incidental alusión a la pluma por parte del gracioso Fabio, que con ella se refiere a la actividad de los escribanos («Ni de escribano tampoco [diré bien], / que no quiero que las plumas, / de que hay infinitas sumas, / me tengan por necio y loco», vv. 639-642), en el tono jocoso y satírico que le corresponde.

Las referencias a la pintura que hemos enumerado, confieren a los tres retratos que de forma más elaborada se presentan en el texto un alcance que va más allá de los consabidos y casi obligados pasajes de raíz petrarquista (recurrentes en numerosas comedias, así como en la poesía de Lope y de otros poetas del Siglo de Oro), ${ }^{12}$ y elevan cada uno de ellos al rango de écfrasis, entendiendo el vocablo especialmente en su original y más antiguo significado de descripción extensa, detallada y vívida o representación verbal que permite presentar un objeto ante los ojos: ${ }^{13}$ los retratos considerados convierten, al hacerse las palabras pinceles, a la persona retratada (que siempre es la hermosa Duquesa, bien con su identidad auténtica, bien con una fingida) en una viva obra de arte. Veamos el primero de ellos, destinado a dejar secuelas en el desarrollo de la intriga:

DON CÉSAR

$$
\begin{aligned}
& \text { Llegué a Milán, adonde ya tenía } \\
& \text { la Reina mi señora prevenido } \\
& \text { tan gran recibimiento, que sería } \\
& \text { cansado y imposible referido. } \\
& \text { Entré en palacio donde el sol ardía } \\
& \text { debajo de un dosel de oro vestido, }
\end{aligned}
$$

12. Véase Manero Sorolla, quien recuerda que gran parte de la imaginería lírica fijada por el propio Petrarca, tan influyente en el Siglo de Oro (y por ella observada analíticamente en sus componentes), procede en realidad de mundos poéticos anteriores al mismo poeta italiano, como «la lírica latina, trovadoresca o stilnovista» (1992: 6); cf. también Manero Sorolla (2005); la vertiente popular del retrato de la dama comparte algunos rasgos e imágenes con la tradición culta, según ha vuelto a recordar recientemente Mañero Lozano (2016). Sobre la poesía que en el Quinientos se refiere a retratos pictóricos, véase el libro de Bolzoni (2008) y, en la vertiente hispánica, el excelente artículo de Gargano (2012), además del de Ponce Cárdenas (2012). A este último (2016) se debe también una indagación sobre poemas epigramáticos inscritos en retratos reales.

13. La acepción original y menos restringida de écfrasis surgió en el contexto helenístico de la Segunda Sofística (siglos III-IV a.C.) y se refería a la descripción verbal de cosas reales o representadas (Krieger 1992: 7), como en Hermógenes; la segunda acepción, ya presente en la Antigüedad y relacionada especialmente con la descripción pormenorizada de obras de arte, fue usada explícitamente por vez primera por Filóstrato de Lemnos (cf. Sánchez Jiménez 2011: 105, con bibliografía). Sobre el alcance del concepto y su uso literario, véase Venturi (2004); en castellano, pueden leerse las atinadas consideraciones de Pineda (2000). Sobre concretas manifestaciones en el teatro de Lope, véanse Ambrose (2004), De Armas (2008 y 2013) —quien tiene varios y muy valiosos trabajos precedentes a esta última fecha sobre la presencia de la pintura y lo ecfrástico en Lope y en Cervantes- y Vélez-Sainz (2015). Para manifestaciones en la poesía del Fénix, véanse Bergmann (1986), Vosters (1987 y 1990, que también alude a obras teatrales), Guillén (1995), Pedraza Jiménez (2012) y Botello (2016). 
dando con dos bellisímas estrellas rayos al cielo y al amor centellas.

Si le viera Faetón, estoy muy cierto que no pidiera al Sol su carro de oro, que allí quedara de sus rayos muerto, sin quemar el León ni arder el Toro. Entré, desde la puerta descubierto, besando el suelo en su real decoro, y de su luz enamorado y ciego parecí mariposa de su fuego.

¿No ha visto Vuestra Alteza algún villano mirarle cuando pasa por su aldea, que sin mover el pie ni alzar la mano toda la vista en su persona emplea? Ansí miré su rostro soberano, mayor que toda imaginable idea; ansí quedé del no pensado caso, pidiendo el alma a su belleza paso.

Diome licencia con mover el suyo de la grada en que el sol llama al aurora. Llegué, besé su mano en nombre tuyo, dile la carta, que aún me admiro agora no de turbarme - mi ignorancia arguyo en la presencia de tan gran señora-, sino de no saber, por su blancura, cuál fue el papel, pues fue la carta obscura.

La carta guarneció de dos corales, quiero decir que la besó y, teñido en púrpura el marfil, fueron iguales en la color el rostro y el vestido; $y$ con ser en un punto efectos tales pensé que ya me había respondido, porque me dio, por sosegar mis miedos, cinco billetes en los cinco dedos.

Referirte, señor, tantos favores como me hizo hasta partir, sería contar luces al cielo, al campo flores y reducir la edad del tiempo a un día. Las fiestas no las vio Milán mejores, la noche imaginó que Roma ardía y con doseles de humo y de centellas se encubrió la ciudad a las estrellas.

En las fiestas, señor, y los torneos mostró Milán en infinitas sumas colores, bordaduras y trofeos, armas francesas y africanas plumas. Quien ver quisiera serafines feos, porque la dicha de tu bien presumas, 
viera las damas de esta fiesta un día

que la Duquesa celestial salía:

tal vez de plata, entre uno y otro velo,

daba luz a las luces de las salas,

que para parecer ángel del cielo

era el cabello sol, los velos alas;

tal vez, con dulce admiración del cielo,

a Venus retrató, tal vez a Palas,

porque si Paris su belleza viera,

ni Elena fuera vil, ni Troya ardiera.

Partimos, finalmente, acompañados

de todo el vulgo, de tu bien gozoso,

los altos montes convirtiendo en prados

el sol divino de su rostro hermoso.

Mirábanla los pueblos admirados, echando bendiciones al dichoso

a cuyo lado amanecer tenía

la misma luz con que se afeita el día.

A diez leguas de aquí la dejo agora, para que des el orden que conviene en recibir la Reina mi seńora, que a honrar tus brazos y estos reinos viene, como previene el sol la blanca aurora: no menos de colores se previene

Nápoles bella, y como a esposa tuya, a dońa Juana Esforcia, reina suya;

la cual, señor, como alcanzara Apeles, el célebre Timantes o Lisipo,

hicieran más famosos sus pinceles, y más glorioso al hijo de Filipo;

a rosas, a azucenas, a claveles, al marfil, a las perlas la anticipo. ¡Dichoso tú que gozarás la joya que honrara a Grecia y abrasara a Troya!

Desarrollado en elegantes octavas, ${ }^{14}$ el retrato verbal realizado por don César procede de quien ha podido contemplar directamente el objeto de tanta hermosura. Se trata de un parlamento sembrado de ecos neoplatónicos: la belleza se ha comunicado a través de la vista y si los ojos de la Duquesa emanan luz, su figura es celestial y es comparable con la de un ángel, con mujeres de la mitología y resulta digna del pincel de excelsos artistas de la Antigüedad; pero también se acompaña a virtudes interiores, como la liberalidad que mues-

14. Ponce Cárdenas (2012) se ha demorado en el contexto cultural italiano a partir del cual varios poetas espańoles del siglo Xvi escribieron, usando precisamente octavas sueltas, composiciones breves consagradas a retratos. 
tra en las suntuosas fiestas que Milán ha reservado al embajador de Nápoles (vv. 177-184). Captamos, además, cierto deslumbramiento del "pintor» ante la hiperbólica belleza de la dama retratada, aunque ello no llegue a cuajar en un topos del retrato femenino especialmente presente cuando está en juego la comparación entre una efigie pictórica y el modelo natural, es decir, la duda de que aquella (en nuestro caso el retrato verbal) consiga representar dignamente este (Gargano 2012: 56).

En el tercer acto, después de escuchar la descripción de Roberto que reproducimos a continuación, el Rey equiparará explícitamente la dama desconocida a una pintura (vv. 2045-2052), dudando, no habiéndola visto, que la hermosura de la mujer pueda estar a la altura de su retrato y, de alguna forma, que la naturaleza pueda imponerse al arte: ${ }^{15}$

$\begin{array}{ll}\text { RoBerTo } & \text { Pasando ya sin temor } \\ \text { las puertas de Celia bella, } & \\ \text { pues ya los desprecios de ella } & \\ \text { ponen templanza en mi amor, } & \\ \text { apear de un coche vi } & \\ \text { una mujer que alabarte } & \\ \text { quisiera, a no ser el arte } & \\ \text { de tanta sospecha en ti, } & \\ \text { pues para ser peregrina, } & 2000 \\ \text { en peregrino valor } & \\ \text { era la madre de Amor } & \\ \text { en forma de peregrina. } & \\ \quad \text { El cabello, que hurtó al mar } & \\ \text { olas que al viento ligero } & 2005 \\ \text { mueve, cubría un sombrero } & \\ \text { que se dejaba mirar, } & \\ \quad \text { que nadie mirar pudiera } & \\ \text { el oro de su guirnalda, } \\ \text { si del sombrero la falda } \\ \text { de nube al sol no sirviera. } \\ \quad \text { El rostro Naturaleza } \\ \text { formó con tal armonía, } \\ \text { que excedió lo que sabía } \\ \text { en su divina belleza. } \\ \text { La esclavina era locura } \\ \text { querértela yo pintar, } \\ \text { que se debió de formar } \\ \text { de esclavos de su hermosura. }\end{array}$

15. Supuesto, el primero, que evidentemente el desarrollo de la acción acabará contradiciendo. Pocos años más tarde, en una silva incluida en el Laurel de Apolo (Vega 2004: 678-681) y dedicada a un cuadro que Rubens hizo de Felipe IV, Lope sugerirá que el arte puede dejar en la sombra a la naturaleza, como manifiesta el análisis que del poema hizo Vosters (1987). 
Lo que a la margen del pie la túnica descubría, oro, señor, parecía $\mathrm{y}$ imaginaciones fue.

¿No has visto los arreboles 2025 con que sale el sol del mar, que no se dejan mirar y parecen muchos soles?

Pues de esta suerte brillaba a cualquiera movimiento

la basa del fundamento y aquella imagen formaba.

Entrose, al fin, recibida de Celia, y quedé, señor, entre confusión y amor, toda el alma divirtida.

En su descripción, Roberto equipara la desconocida a Venus (v. 2003: «era la madre de Amor»), volviendo con ello a un término de comparación que ya había usado don César, y acude al consabido movimiento descendente de la mirada (del cabello — v. 2005— pasa al rostro — v. 2013 —, y de este, al pie — v. 2021—), prestando a la vez atención al atuendo de la dama (allí están: el sombrero - - v. 2007—; la esclavina —v. 2017—, prenda usada para una agudeza y propia de peregrinos, junto al bordón que aquí no se menciona; y la túnica —v. 2022-). Es de notar que el caballero, la figura de menor relevancia social entre los «retratistas» de la obra, limita su atención exclusivamente al aspecto exterior de la observada, por mucho que su alma haya quedado conquistada por la visión (en el «Prólogo dialogístico», por lo demás, leemos: «¿qué verán los ojos que no vea el alma?»).

En el mismo acto conclusivo de la comedia, aparece finalmente la descripción del propio Rey (que desencadena a continuación la previsible crítica de César, contrariado por las consecuencias sufridas a raíz del elogio hecho en su momento):

REY

Hoy ha llegado,

2290

vestida de peregrina

y peregrino retrato

de los ángeles del cielo;

que es gran señora está claro, porque su talle lo dice,

su vestido y sus crïados.

Como de fúlgidas nubes

se forma del cielo el manto,

de diamantes su vestido,

o sus ojos me engañaron,

que como el sol encendido

hace parecer dorados 
los campos, los edificios, ansí del vestido el manto bordaba el sol de sus ojos, ojos que no hicieran casto en Cartago a Cipión, en Grecia al fuerte Alejandro.

Sus dos nińas, dos amores, jugaban con flechas y arcos;

de sus pestańas y cejas

iban mil almas colgando;

el campo de sus mejillas, ¿qué flores tienen los campos, qué nieve tienen los montes con que poder compararlos? La nieve es negra, las flores feas, en viendo mezclados con azucenas claveles, con rosas jazmines blancos. ¿No has visto, César, la risa de algún arroyuelo manso, que en dos márgenes de flores va las arenas contando y, como músico diestro, con diversidad de pasos trina en los altos la voz y va sonoro en los bajos? Pues imagina en la suya aquel mismo curso blando y otra cosa más sutil, aunque parezca milagro: que es la voz para el oído, y la suya puede tanto, que es para los ojos, viendo que la obliga a abrir los labios.

Ya basándose directamente en su propia vista, el Rey vuelve a fijarse en elementos canónicos (por ejemplo, la condición celestial de la retratada: «peregrino retrato / de los ángeles del cielo», vv. 2292-2293) y en partes reveladoras del rostro de la mujer, sobre todo los ojos (v. 2300), a los que se acompañan las mejillas (v. 2313). El personaje también se fija en la extracción social de quien cree que es una romera, pues subraya que ha de tratarse en realidad de una "gran señora», por talle, vestido y criados (suponemos por la apariencia y número de ellos: véanse vv. 2295-2296). Añade, sin embargo, un aspecto que no estaba en las descripciones de quienes, entre sus súbditos, le precedió: la voz, considerada ahora elemento de indudable fascinación. Este rasgo cobrará una notable importancia en Lo que puede la aprehensión de Moreto, que se inspira en la pieza de Lope teniendo en cuenta, a la vez, la comedia tirsiana La celosa de si misma 
(de 1622-1623) ${ }^{16}$ y la calderoniana La desdicha de la voz (autógrafo de mayo de 1639), en la que la voz de dońa Beatriz y las canciones por ella entonadas desempeñan un papel central. Kennedy (1932: 179-180) en su día hizo notar cómo la relación entre don César y la Duquesa, núcleo de nuestra comedia, es desplazada por Moreto al plano de la intriga secundaria (subplot); más recientemente, Domínguez Matito (2012: 91-93) ha reincidido de forma oportuna en la profunda reformulación de los materiales anteriores que supone la comedia moretiana, en la que la voz sigue teniendo un papel destacado.

Volviendo a Mirad a quién alabáis, resulta evidente la capacidad que poseen los retratos de la dama, más allá de su conocida naturaleza tópica, de pintar con la palabra y suscitar pasiones en escena, lo que se convierte en última instancia en un testimonio más, si no en un alarde, de la maestría formal de Lope en años convulsos para su reinado poético y dramático, al mismo tiempo que una mise en abyme de su arte teatral (en la que, no lo olvidemos, tanta parte también tenían los oídos, capaces de retratar "en la imaginación por ideas lo que oyen", como el dramaturgo vuelve a recordar en el ya citado «Prólogo dialogístico» de la Parte $X V I)$. En efecto, y prescindiendo de la endeblez del asunto inicial en que se basa el desarrollo de la intriga (endeblez que el Lope maduro de estos años debió de asumir de forma consciente), en el recién mencionado "Prólogo dialogístico» el dramaturgo hace elogiar al personaje del Teatro seis obras de la recopilación: la mitad de los textos teatrales en ella contenidos, entre los que se encuentra Mirad a quién alabáis. ${ }^{17} \mathrm{Al}$ declarar su especial aprecio por estas piezas, Lope quizás esté rebatiendo las acusaciones de escribir a vuelapluma y promocionando unos textos que en su opinión destacarían por el valor y la eficacia formales y poético-literarios (características que los distanciarían idealmente del teatro de aparato e indirectamente del cosmos culterano), ${ }^{18}$ además de poder resultar más afines por tema (cortesano o mitológico) al horizonte aristocrático en el neurálgico año de 1621, en el que, entre la suma del privilegio de la Parte XVI (octubre de 1620) y su puesta en venta (diciembre de 1621), tiene lugar nada menos que un cambio de monarca y salen la Parte XVII y La Filomena; recuerdo que en el tratamiento deparado en algunos de los poemas de esta última a la propia imaginería de la belleza femenina se han detectado marcas novedosas, sea por evolución interna de la expresión poética de Lope sea por el impacto de la poesía gongorina. ${ }^{19}$ Así, quizás no sea del todo descabellado pensar que el título

16. Como ha observado más en detalle Vitse (2004: 200), en esta comedia urbana es la mano de la dama (dońa Magdalena) la que recibe arrebatados calificativos por parte de don Melchor.

17. Cf. las palabras que Lope pone en boca del Teatro: «Mirad a quién alabáis, El Perseo, El laberinto y Los Prados, el Adonis y Felisarda están de suerte escritas que parece que [el autor] se detuvo en ellas». 18. Case (1979) lo consideró un caso de «autoevaluación» (self-evaluation); nos parecen evidentes los fines de autopromoción del dramaturgo.

19. Véase Allen (1974: 13). Sobre la vertiente antigongorina de las polémicas lopescas, especialmente en la obra no dramática y en los años de senectute, véase M. Blanco (2008), que también 
de sabor sentencioso de la comedia, Mirad a quién alabáis, y la advertencia en él contenida puedan entrañar un aviso para el público y los lectores: frente a los rivales literarios, el dramaturgo y poeta ofrece una renovada muestra de su arte (que, como el de algunos pintores, "excede / tal vez a Naturaleza», como dicen los vv. 425-426) y se presenta de forma implícita como quien se resiste a ceder a los vientos de las modas y de las tendencias. En este sentido el texto no evita, en un pasaje de lectura algo trabajosa pero cuyo sentido global no deja dudas, una manifiesta pulla contra los culteranos. Obviamente la encontramos en boca del criado y gracioso Fabio (vv. 651-657): «y la gente de esta seta [los poetas] / sufrirá una melecina / primero que al que se inclina / alaben a otro poeta; / ¿pues alabar latinantes? / Eso no: sepan primero / romance».

dedica unas páginas a la década de 1610, marcada por la irrupción en el horizonte literario de los poemas mayores de Góngora, la polémica desencadenada por la Spongia de Pedro Torres Rámila (1617) y la contundente réplica que a ella supuso la Expostulatio del ańo siguiente (texto, este último, que ha gozado en años recientes de significativas aportaciones críticas). 


\section{Bibliografía}

Allen, John J., «Lope de Vega y la imaginería petrarquista de la belleza femenina», Estudios de hispanistas norteamericanos dedicados a Helmut Hatzfeld con motivo de su 80 aniversario, eds. Josep M. Solá-Solé, Alessandro Crisafulli, Bruno Damiani, Barcelona, Hispam, 1974, 5-23.

Ambrose, Timothy, «Lope and Titian: the Goddess as Emblem of Sacred and Profane Love», Writing for the Eyes in the Spanish Golden Age, ed. Frederick de Armas, Lewisburg, PA, Bucknell University Press, 2004, 167-184.

Antonucci, Fausta, «Algunos ejemplos de hibridación genérica en el teatro de Lope: reflexiones al hilo de unas búsquedas en la base de datos Artelope», Teatro de palabras: revista sobre teatro áureo, 7 (2013), 141-158.

Arata, Stefano, Miguel Sánchez il "Divino» e la nascita della "comedia nueva», Salamanca, Universidad de Salamanca, 1989.

Armas, Frederick A. de, «Lope de Vega's Speaking Pictures: Tantalizing Titians and Forbidden Michelangelos in La quinta de Florencia», A Companion to Lope de Vega, eds. Alexander Samson y Johnathan Thacker, London, Tamesis, 2008, 171-182.

—, “¿Es éste Adonis?”. La écfrasis y los efectos del arte en el teatro de Lope de Vega», eHumanista, 24 (2013), 60-79.

Arredondo Sirodey, Soledad, «El pincel y la pluma. Sobre retratos, paisajes y bodegones en la literatura del Siglo de Oro", Anales de Historia del Arte, número extraordinario, 1 (2008), 151-169.

Badía Herrera, Josefa, Los primeros pasos en la comedia nueva: textos y géneros en la colección teatral del Conde de Gondomar, Madrid-Frankfurt am Main, TC/12-Iberoamericana-Vervuert, 2014.

—, «La comedia palatina en la gestación de la comedia nueva», La comedia palatina del Siglo de Oro. Cuadernos de teatro clásico, dir. Miguel Zugasti, ed. Mar Zubieta, número monográfico, 31 (2015), 103-116.

Bergmann, Emilie, "The Painting's Observer in the Epic Canvas: La hermosura de Angélica», Comparative Literature, 38 (1986), 270-288.

Blanco, Mercedes, «La polémica como fermento creativo en el Lope de la vejez (1621-1635)», Anuario Lope de Vega, 14 (2008), 37-66.

Bolzoni, Lina, Poesia e ritratto nel Rinascimento, Bari, Laterza, 2008.

Botello, Jesús, "Una écfrasis doble en Lope de Vega. "Al triunfo de Judit"”, Hispanófila, 176 (2016), 55-68.

Calderón de la Barca, Pedro, La desdicha de la voz, ed. T. R. A. Mason, Liverpool, Liverpool University Press, 2003.

Calvo Serraller, Francisco, «El pincel y la palabra: una hermandad singular en el Barroco español», El Siglo de Oro de la pintura española, Madrid, Mondadori, 1991, 187-204.

Camón Aznar, José, "Citas de arte en el teatro de Lope de Vega», Revista de Ideas Estéticas, 10 (1945), 233-274. 
—, Dominico Greco, 2 vols., Madrid, Espasa-Calpe, 1970, 2a ed.

Case, Thomas E., "A Case of Self-Evaluation in Lope», Revista de Estudios Hispánicos, 13, 2 (1979), 253-267.

Crvit, Pierre, «Ut pictura poesis en los preliminares del libro español del Siglo de Oro: el poema al retrato grabado", Actas del IV Congreso Internacional de la Asociación Internacional Siglo de Oro (AISO), eds. Ma Cruz García de Enterría y Alicia Cordón Mesa, Alcalá de Henares, Universidad de Alcalá, 1996, 419-432.

D’Artors, Florence, ed., «Prólogo dialogístico», Les idées du théâtre, 21.03.2016, $<$ http://www.idt.paris-sorbonne.fr/html/VegaPrologoParteXVI.html>.

Di Pastena, Enrico, "Prólogo», Lope de Vega, Mirad a quién alabáis, en Comedias de Lope de Vega. Parte XVI, coord. Luigi Giuliani, vol. 1, Madrid, Gredos, 533-676.

Domínguez Matito, Francisco, «El acento equívoco. Variantes sobre un motivo desde Lope a Moreto, pasando por Tirso y Calderón", Iberoromania, 75-76, 1 (2012), 85-103.

EgIDO, Aurora, «La página y el lienzo: sobre las relaciones entre poesía y pintura», Fronteras de la poesía en el Barroco, Barcelona, Crítica, 1990, 164-197.

Entrambasaguas, Joaquín de, "Lope de Vega y Rubens y, al fondo, Miguel Ángel», Punta Europa, 9, 99-100 (1964), 52-67; reimpresión con correcciones y adiciones: Joaquín de Entrambasaguas, Estudios y ensayos sobre Góngora y el Barroco, Madrid, Editora Nacional, 1975, 211-225.

Ferrer Valls, Teresa, «Géneros y conflictos en los autores de la escuela dramática valenciana", Edad de Oro, 16 (1997), 137-148.

Gargano, Antonio, "L'ombra ignuda entro 'l pensier figura". La tradición lírica sobre el retrato de la dama en la poesía del siglo XVI», Poesía y pintura en el Siglo de Oro, Criticón, número monográfico, 114 (2012), 33-69.

Giuliani, Luigi, y D’Artors, Florence, «La Decimasexta Parte: historia editorial», Comedias de Lope de Vega. Parte XVI, vol. 1, Madrid, Gredos, 2017, 1-30.

Guillén, Felisa, «Ekphrasis e imitación en la Jerusalén conquistada», Hispania, 78, 2 (1995), 231-239.

Kennedy, Ruth Lee, The Dramatic Art of Moreto, Philadelphia, s.n., 1932. Es reimpresión de Smith College Studies in Modern Languages, 13, 1-4 (1931-1932).

Krieger, Murray, Ekphrasis. The Illusion of the Natural Sign, Baltimore, John Hopkins University Press, 1992.

Lleó Cañal, Vicente, «Ut pictura poesis (pintores y poetas en la Sevilla del Siglo de Oro)», Minervae Baeticae, 35 (2007), 33-69.

Manero Sorolla, María del Pilar, «La configuración imagínistica de la dama en la lírica española del Renacimiento. La tradición petrarquista", Boletín de la Biblioteca de Menéndez Pelayo, 68 (1992), 5-71.

—, «Los cánones del retrato femenino en el Canzoniere. Difusión y recreación en la lírica española del Renacimiento", Cuadernos de filología italiana, número extraordinario, 12 (2005), 247-260. 
Mañero Lozano, David, «Los retratos de la dama. Recursos de traslación y propagación literaria en la confluencia de la tradición popular y culta», $R i$ vista di Filologia e Letterature Ispaniche, 19 (2016), 9-41.

Martín Gayango, María de los Ángeles, «Ut pictura poesis en la historia: Del siglo XVI al siglo XX», Tiempo y sociedad, 11 (2013), 166-182.

Mexía, Pedro, Silva de varia lección, ed. Antonio Castro Díaz, 2 vols., Madrid, Cátedra, 1989-1990.

Molina, Tirso de, La celosa de sí misma, ed. Gregorio Torres Nebrera, Madrid, Cátedra, 2005.

Moreto, Agustín, Lo que puede la aprehensión, ed. Francisco Domínguez Matito, en Agustín Moreto, Primera Parte de Comedias, vol. 4, Kassel, Reichenberger, 2010, 399-590.

Ojeda Calvo, Valle, "Introducción", El hijo de la cuna de Sevilla, Kassel, Reichenberger, 1996, 1-149.

OlezA, Joan, «La comedia y la tragedia palatinas: modalidades del Arte Nuevo», Edad de Oro, 16 (1997), 235-251.

Oleza, Joan y Antonucci, Fausta, «La arquitectura de géneros en la Comedia Nueva: diversidad y transformaciones», Varia lección de teatro áureo, Rilce, eds. Álvaro Baraibar y Mariela Insúa, número monográfico, 29, 3 (2013), 689-741.

Pedraza Jiménez, Felipe B., «Plástica y poética en el primer Lope. El entorno de las Rimas», "Por tal variedad tiene belleza». Omaggio a Maria Grazia Profeti, eds. Antonella Gallo y Katerina Vaiopoulos, Firenze, Alinea, 2012, 211-225.

Pérez, Luis Carlos y Sánchez Escribano, Federico, Afirmaciones de Lope de Vega sobre preceptiva dramática, Madrid, CSIC, 1961.

Pineda, Victoria, "La invención de la écfrasis», Homenaje a la profesora Carmen Pérez Romero, Cáceres, Universidad de Extremadura, 2000, 251-262.

Plinio el Viejo, Naturalis historia: Natural History, libri XXIII-XXXV, trad. H. Rackam, vol. 9, Cambridge, Massachusetts - London, Harvard University Press - William Heinemann Ltd (The Loeb Classical Library), 1968.

Ponce Cárdenas, Jesús, «La octava real y el arte del retrato en el Renacimiento", Poesía y pintura en el Siglo de Oro, Criticón, número monográfico, 114 (2012), 71-100.

—, «In pictura poesis: epigramas renacentistas insertos en retratos», Studia Aurea, 10 (2016), 131-152.

Portús Pérez, Javier, Lope de Vega y las artes plásticas (estudio sobre las relaciones entre pintura y poesía en la España del Siglo de Oro), Madrid, Universidad Complutense de Madrid, 1992.

-, Pintura y pensamiento en la España de Lope de Vega, Hondarribia, Nerea, 1999.

Rennert, Hugo A.; Castro, Américo, Vida de Lope de Vega (1562-1635), Salamanca, Anaya, 1968. 
Sánchez Jiménez, Antonio, El pincel y el Fénix. Pintura y literatura en la obra de Félix de Lope Vega Carpio, Madrid, Iberoamericana, 2011.

Vega, Lope de, Laurel de Apolo, en Lope de Vega, Poesía, V, ed. Antonio Carreño, Madrid, Biblioteca Castro, 2004, 439-701.

-, El castigo sin venganza, ed. Antonio Carreño, $8^{a}$ ed. revisada, Madrid, Cátedra, 2010.

—, "Prólogo dialogístico", Decimasexta parte de comedias de Lope de Vega Carpio, ed. Florence d'Artois, Les idées du théâtre. 21-03-2016, <http://www.idt. paris-sorbonne.fr/html/VegaPrologoParteXVI.html>.

—, Mirad a quién alabáis, ed. Enrico Di Pastena, Comedias de Lope de Vega. Parte XVI, coords. Luigi Giuliani y Florence d'Artois, vol. 1, Madrid, Gredos, 2017, 533-676.

VÉLEZ-SAInZ, Julio, «Écfrasis y artes plásticas en El vellocino de oro de Lope de Vega», coord. Lola González, Pluma y pinceles son iguales. Teatro y pintura en el Siglo de Oro, Lleida, Centre d'Art d'Ėpoca Moderna (CAEM) - Edicions i Publicacions de la Universitat de Lleida, 2015, 151-167.

Venturi, Gianni, «Introduzione», eds. Gianni Venturi, Monica Farnetti, Ecfrasi. Modelli ed esempi fra Medioevo e Rinascimento, vol. 1, Roma, Bulzoni, 2004, 9-13.

VITSE, Marc, "La burla en El burlador de Sevilla y La celosa de sí misma de Tirso de Molina», Tirso de Molina en la Compañía Nacional de Teatro Clásico, Cuadernos de Teatro Clásico, dir. Ignacio Arellano, número monográfico, 18 (2004), 193-213.

Vosters, Simon A., "Lope de Vega y la pintura como imitación de la Naturaleza", Edad de Oro, 6 (1987), 267-285.

—, Rubens y España. Estudio histórico y artístico sobre la estética del Barroco, Madrid, Cátedra, 1990.

Zugasti, Miguel, «Deslindes de un género dramático mayor: comedia palatina cómica y comedia palatina seria en el Siglo de Oro», La comedia palatina del Siglo de Oro, Cuadernos de teatro clásico, dir. Miguel Zugasti, ed. Mar Zubieta, número monográfico, 31 (2015), 65-102. 
